\title{
Regular Information and Health: Evidence from a Field Experiment with Undergraduate Students
}

\author{
Marianne Bernatzky \\ José María Cabrera \\ Alejandro Cid*
}

July $10^{\text {th }}, 2015$

\begin{abstract}
We run a randomized controlled trial with the aim of evaluating the effects of a health seminar complemented with weekly reminders on health outcomes. Our research design exploits the excess of applicants over the intervention capacity. In this 4-month intervention with undergraduate students, we provide information on preventive behaviors and healthy habits and on how to modify personal behaviors that could derive in chronical illnesses. We find that all students who were subject to the treatment improved their knowledge relative to the control group. But they were not able to translate it into healthier behaviors, neither self-reported nor objectively measured by a physician. We hypothesize that high discount rates, overconfidence and the lack of complementary inputs may explain our findings.
\end{abstract}

Keywords: randomized trial, exercise, healthy habits, text message.

* mbernatzky@correo.um.edu.uy; jmcabrera@um.edu.uy; acid@um.edu.uy Universidad de Montevideo.

We thank the physicians Andrea Giménez, Mary Armúa, Roberto Rivas, Virginia Longo and Alicia Fernández for their valuable experience and contribution to the health seminar. We are also grateful to Verónica Cousillas for her research assistance. Ana Balsa and Juan Dubra provided very helpful comments. 


\section{Introduction}

Though the benefits of physical exercise and a nutritious diet on people's health and well-being have been extensively reported (e.g., Warburton, Nicol \& Bredin, 2006; Reimers, Knapp \& Reimers, 2012; Deslandes et al., 2009; Dietary Guidelines for Americans, 2010), the results of experimental interventions in the health literature show that providing information on the benefits of exercise and the consequences of risky behaviors is not enough to modify behaviors and to acquire healthier habits (e.g., Balsa, Gandelman \& Porzecanski, 2010; Calfas et al., 2000; Charness \& Gneezy, 2009; Djuric et al., 2010; Hivert et al., 2007; Levitsky et al., 2006; McEachan et al., 2011).

In an attempt to go beyond the simple provision of information on standard healthy habits, the program 'Health \& Academic Achievement' implemented at Universidad de Montevideo in Uruguay (UM) tries to modify personal behaviors of undergraduate students that could derive in chronical illnesses with a different approach. The program provides students with intensive training sessions during 4 days with physicians in Montevideo specialized on drugs, physical activity and nutrition. In each session they offered theoretical fundamentals and practical guidelines to acquire healthier habits (attendance was mandatory for those registered). This health intervention not only offered professional guidance, but also included the use of Information and Communications Technologies (ICTs) during the following months to enhance the content of the lessons. Participants received weekly reminders on the importance of exercise and a nutritious diet: SMS to their mobile phones, messages through Facebook and the exposure to banners through the student's intranet webpage at the university. We evaluate the effects of this health intervention with a randomized controlled trial assigning students to a treatment or a control group. The research design exploits the oversubscription to the program. In sum, we evaluate a comprehensive intervention with undergraduate students attending a private university in a developing country that combines information delivered through an intensive seminar and through weekly reminders. We measure the effects on knowledge acquired and habit formation.

We find that students who were subject to the intervention improved the information on healthy behaviors, measured through a test at the follow-up survey. In addition, our findings suggest that the program was not able to modify the behavior of the students (measured through self-reported surveys and by biometric measurements collected by physicians). Our results suggest that providing information about the link between healthy behaviors and future outcomes does not translate knowledge into better outcomes. We hypothesize that high discount rates and the lack of complementary inputs may explain our results, at least in the short term. These findings shed light on improvements that could take place in future interventions to improve the behaviors of a population of undergraduate students.

The rest of the paper is organized as follows: section II presents background literature, section III describes the program and explains the experiment's design, section IV presents the econometric model and results, section $\mathrm{V}$ presents the conclusions and VI the discussion. 


\section{Background Literature}

There is a vast body of health literature related to the impact of physical exercise on people's health and well-being. Warburton, Nicol and Bredin (2006) review the existing literature and provide evidence that physical activities play an important role in the primary and secondary prevention of chronic diseases such as type 2 diabetes, cardiovascular disease, cancer, hypertension, obesity, depression and osteoporosis. Reimers, Knapp and Reimers (2012) synthesize previous studies on the relation of physical exercise and life expectancy and find that regular physical activity is associated with an increase in life expectancy. Lee et al. (2012) confirm these results by estimating the effects of physical inactivity on heart disease, type 2 diabetes, cancer and premature mortality. In addition, the relation between mental health and physical activity has been extensively investigated and was reviewed by Deslandes et al. (2009). They find that physical activity is associated with an improvement on mental diseases such as depression, Alzheimer's and Parkinson's disease.

Preventing chronic diseases requires not only regular physical exercise but also having a nutritious diet (Physical Activity Guidelines Advisory Committee Report, 2008). The daily intake of fruits and vegetables is associated with a rise in happiness and mental health (Blanchflower, 2012). Moreover, the intake of at least $2 \frac{1}{2} 2$ cups of vegetables and fruits per day is associated with a reduced risk of cardiovascular disease (Dietary Guidelines for Americans, 2010). Given the evident benefits of exercising and a healthy diet, the Physical Activity Guidelines Advisory Committee in the U.S. as well as the World Health Organization have published guidelines to prevent chronic diseases and to promote healthy habits. As an example, among the recommendations, it is advisable to exercise $150 \mathrm{~min}$ or more per week. Such a recommendation could be very difficult to follow if, for example, the benefits of incurring in this activity are perceived as very distant in the future and the effort required in the present is too high.

Providing information about the benefits of exercise, healthy habits and risky behaviors may not produce the desired results. Charness and Gneezy (2009) document this in one of their studies where they randomly assign a pool of 120 students at the University of Chicago to three different treatments. In a meeting at the university, everyone received a handout of the benefits of exercise. Eighty of the participants were offered \$25 if they attended the gym at least once in the following week to the meeting. Then, forty of them received a $\$ 100$ incentive to attend the gym at least eight times in the following four weeks. They find that both regular and non-regular gym attendees prior to the experiment in the control group experience an insignificant downward shift in their gym attendance. Balsa, Gandelman and Porzecanski (2010) provided information to adolescents through the Internet (website and e-mails) and SMS (8 emails and 7 SMS were sent in a period of three months) about the risks and consequences of substance use. They find that the intervention improved their knowledge about risks but there were no significant changes in behavior.

There are some studies that report successful interventions which seem to be effective at inducing changes in health behavior. They use text messages as regular reminders or 
use them with informational or motivational purposes. Calzolari and Nardotto (2015) document the effects of sending reminders (on the possibility of exercising) to a sample of college students. They find that reminders induce users to increase their levels of physical exercise and maintain them for a prolonged period. They also show that the mechanism behind their finding is that reminders refocus the student's attention towards the investment opportunity: gym attendance. Fjeldsoe, Marshall and Miller (2009) review 4 studies focused on preventive health and 10 studies focused on clinical care that used tailored SMS to deliver information. Positive changes in outcomes arise in 13 of the 14 studies reviewed by the authors. A related finding is documented in Woolford et al. (2010). They send tailored information through text messages to adolescents enrolled in a weight-management program. Participants revealed that the messages were personally relevant and helped them to keep focused on weight management.

In an attempt to modify personal behaviors that could derive in chronical illnesses, the intervention 'Health \& Academic Achievement' differs from a typical health workshop. In addition to the seminar that informed students on preventive measures, healthy habits and on their repercussion on academic achievement, it was complemented with weekly reminders on the importance of exercise and a nutritious diet. We contrast two hypotheses. The first states that there will be no changes in the student's behavior once the intervention is finished. Fryer (2013) looks at the problem of a student choosing the level of effort to invest in her studies. He explains that high discount rates and lack of complementary inputs may lead to the option of not working hard. The rival hypothesis (Calzolari and Nardoto, 2015) states that in a model with participants with limited attention, the exposure to frequent messages with information could lead to refocus the students' attention towards the investment activity and therefore a change in behavior arises.

\section{Program and Experiment Design}

Students majoring in diverse areas (Economics, Management, International Business Economics, Accountancy, Humanities, Communication and Engineering) at Universidad de Montevideo (UM) -a private university in Uruguay that serves approximately 3000 students and is ranked among the best universities in the countrytook the health intervention in April of 2013. It was organized by the Economics Department and the School of Biomedicine, and the instructors were physicians specialized on drugs, physical activity and nutrition. In March 2013, the university opened an enrollment window inviting students to apply for attending the health intervention. The intervention 'Health \& Academic Achievement' had 33 places available and 68 students applied.

The seminar provided students with concrete information on how healthy habits would contribute to an improvement in academic performance and how these were compatible with other activities such as hobbies or personal interests. In addition, the 
seminar encouraged students to identify personal behaviors that could derive in chronical illnesses and to reflect on how these could be avoided. Moreover, the instructors advised students on taking preventive medical examinations in order to detect illnesses at a very early stage and taught students how they could identify symptoms of several diseases. Students were also instructed on the benefits of a healthy diet and properties of natural meals. The seminar was held during four consecutive days, in sessions of 110 minutes. Attendance was mandatory for each of the four days. Teaching assistants marked attendance as students arrived and did not mark a student as attending if they left the classroom before the end of the session.

In addition, the intervention included the delivery of information related to healthy habits- the importance of exercise, preventive measures to avoid diseases, valuable properties of natural meals, etc. -through SMS, a Facebook Group and through the students' personal intranet webpage at UM during 4 months. The content of the messages was extracted from the seminar lessons (e.g. "12 people die per day for causes related to smoking", "seasonal fruits have a higher nutritional value than other fruits"; "oily fish that have high contents of omega 3: tuna, sardine, salmon, horse mackerel", "walking stimulates brain plasticity", "exercise diminishes depression and minimizes anxiety"). Messages were delivered weekly.

In Table 1, we define a set of baseline characteristics and describe the sample of 68 students participating in the intervention. Students are 22 years old on average; they have a mean grade of 6.8 out of $12^{1}$; two-thirds are from the capital of the country, approximately $59 \%$ are female and $22 \%$ of the students come from three private schools in Montevideo. Over $60 \%$ of the sample are not in the labor market. Although the seminar was open to students from several areas, over $76 \%$ of them are majoring in Accountancy, Management and Economics. Nearly 32\% have scholarship at UM and $72 \%$ report that their economic well-being is good or very good. Regarding healthy habits, $21 \%$ are currently smoking. Nearly $76 \%$ drank alcohol in the last 30 days and $27 \%$ of the sample of students drinks alcohol from one to four times a week. On average, students eat vegetables 4.3 days a week and fruits 3.7 days a week, practice sports two hours and a half per week and stay sitting or in a lying position more than 6 hours a day. In addition, $87 \%$ of the students perceive they have a good or very good health condition and over $80 \%$ of the sample made an appointment with a physician in the last 12 months.

\section{[Insert Table 1]}

The intervention evaluates the effects of a health seminar being complemented with weekly reminders -that target the importance of exercise and a healthy diet- delivered to undergraduate students on a variety of outcomes.

We exploit the oversubscription to the program and design a randomized experiment to evaluate the intervention. This allocation rule ensures that the group of students participating in the health intervention - the treatment group - is similar at baseline to

\footnotetext{
${ }^{1}$ This mean grade, credits earned and the percentage of female students are similar to the averages at the University (mean grade: 6.7; credits earned: 158; percentage of female students: $52 \%$ ).
} 
the group of students who are not drawn in the lottery -control group. Prior to randomization (and the surveys), we received the approval of the ethical review board of the university. We use a phase-in design, so all candidates could benefit from the seminar. The seminar had a limited capacity. Treated students attended the seminar during the first semester of the year. We offered students assigned to the control group the opportunity to attend to a health seminar in the second semester of the year.

We employ random assignment because it might be the fairest method to decide which students will participate in the intervention. As the decision to participate in the program was voluntary, we potentially had the problem of self-selection. However, given the oversubscription to the program, we remove the selection bias when we randomize into a treatment and a control group.

In our field experiment, we collect data on 68 students; 33 students were randomly assigned to the treatment group and 35 to the control group. Students in the health seminar automatically received a grading pass of seven -on a scale of 12- when they fulfilled the attendance requirement $(100 \%)$. In order to encourage students to show up at a later stage to collect health indicators, we offered a grade of 12. At the follow-up stage, although the attendance of the control group was voluntary, it was highly recommended before the start of the intervention at the second semester.

\section{Timeline of the Program and Data Collection}

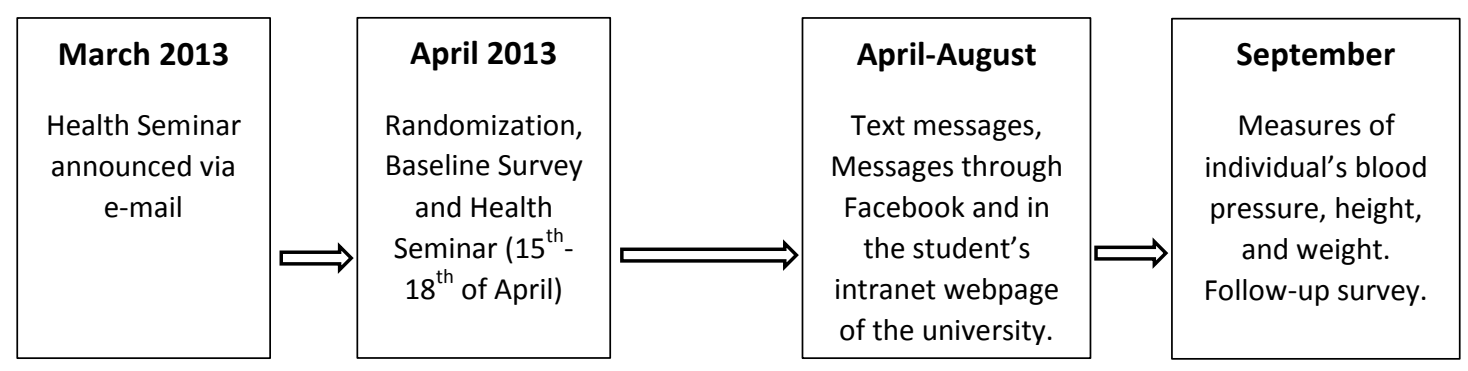

Before drawing the lottery, the research team collected administrative data of the pool of 68 students.

Randomization was executed to achieve balance between the treatment and control group in 8 characteristics ${ }^{2}$. After randomization, but before the seminar started, we collected pre-treatment data on a wide array of students' characteristics such as smoking habits and attitudes towards alcohol, healthy habits and relation with their physician. In Table 2 we present summary statistics by treatment group. Given that

\footnotetext{
2 Gender, region of the country -interior or capital of Uruguay-, major- economics, management or accountancy-, credits earned at college, grade average, scholarship at UM, year starting college and attending to one particular high-school - there is a large proportion of students at UM who had previously attended this high school- before attending college.
} 
only 3 of the 41 p-values estimated are smaller than 0.10 , the randomization was effective at balancing the groups on observable variables ${ }^{3}$.

The follow up questionnaire was implemented four months after the seminar (starting on August 26 $6^{\text {th }}$ ). It was delivered through an online platform. Questions were very similar to the baseline ones, and we added an 18-question test to evaluate the acquisition of knowledge. We were unable to gather information for five students (four from the control group and one from the treatment group). Since answers to the follow-up survey were self-reported, we also hired a physician to collect health measures ${ }^{4}$. In the first weeks of September he was able to collect anthropometric measures of 62 students ( 31 from the treatment group and 31 from the control). Attrition in this case was higher than in the follow up survey, since students had to go to the medical consultation at the University (the survey was on-line, so students could answer from their homes). Some students were abroad, so it was not possible for them to physically attend, and others didn't want to participate at this stage.

Two students who were assigned to the control group managed to receive treatment. Thus, the group who finally received treatment differs slightly from the group initially selected to be treated (the intention to treat group, ITT). The presence of non-compliers may be a threat when detecting the impact of the health intervention. A simple Ordinary Least Squares (OLS) may introduce bias in the impact estimates if selection into the treatment group is not random. Therefore, to address this issue, we use the ITT as an instrument for effective participation and estimate the effects using instrumental variables. As a robustness check, we also use the initial assignment - intention to treat status- as the explanatory variable (results from these regressions are available upon request).

\section{Hypotheses: Possible findings for this experiment}

Our standard null hypothesis states that students do not change their behavior once the intervention is finished. It can be associated to the high costs of making effort in this investment activity or the absence of complements that could incite a change in behavior.

Hypothesis 0: The intervention has no effect on health behavior once the health intervention finishes and reminders on healthy habits are no longer sent to students.

This hypothesis, developed by Fryer (2013) in an educational context, suggests that students cannot translate knowledge into measurable output. He studies the effect of daily SMS with information about the link between human capital and future outcomes. There were no differences in attendance, behavioral incidents and test scores - their investment activities. If future rewards are perceived as very distant in the future, participants could consider the investment activity worthless. Moreover,

\footnotetext{
${ }^{3}$ We have administrative data for the 68 students on the experiment, but we were unable to collect data for one student (both pre-treatment and follow-up data).

${ }^{4}$ When students enrolled for the seminar they were told that, at the end-line evaluation, there was going to be a medical assessment of external health variables (pressure, height and weight).
} 
improvement in education might depend on complements not included in the intervention.

He develops a model to better understand the mechanisms behind the conclusions. A student is choosing the level of effort $\mathrm{E}$ to invest in a costly activity. The production function for academic achievement $\mathrm{A}=\mathrm{F}(\mathrm{E}, \mathrm{K})$ depends on effort and on a vector of $\mathrm{k}-$ characteristics - friends and family behaviors, neighborhood, environment, etc. fixed prior to the intervention- which are complements. The long-term benefits of making effort are $\mathrm{V}(\mathrm{A} ; \mathrm{r})$, where $\mathrm{r}$ is the perceived return to investment. If the student maximizes his utility considering the cost of effort and a discount factor, he may not modify the behavior if the reward is perceived as very distant- in the model, it is represented with a small value of the discount factor. In addition, the production function may have complementarities that combined with effort could make a difference in behavior. If the levels of $\mathrm{K}$ are very low, the return to effort is insignificant and therefore students prefer not to invest in costly activities.

If healthy habits such as exercising or having a nutritious diet are considered investment activities, perceptions of a distant reward or complements not included in the intervention might undermine the objectives of the health intervention.

An alternative hypothesis is offered by Calzolari and Nardotto (2015). They state that giving information regularly to students with limited attention can modify their behavior because students are able to refocus their attention towards the investment activity.

Hypothesis 1: The intervention modifies behavior of students and they engage in healthier habits.

Several studies have documented that reminders with informational or motivational purposes prove to be effective at inducing changes in health behavior. Calzolari and Nardotto (2015) document the effects of weekly reminders on the possibility of exercising to a sample of college students and find that reminders induce users to increase their levels of physical exercise and maintain them for a prolonged period. Fjeldsoe, Marshall and Miller (2009) review 14 studies focused on preventive health and clinical care that used tailored SMS to deliver information and find that positive behavior change outcomes arise in 13 of the 14 studies.

\section{Econometric Model and Results}

We evaluate the effects of the health intervention on a wide array of outcomes. Ideally, we would like to estimate the following equation:

$$
Y_{i}=a+b \text { Participated in the health intervention }{ }_{i}+X_{i}{ }^{\prime} c+e_{i}
$$

Where $Y_{i}$ is the outcome of interest for student $\mathrm{i}$ (health indicators measured by physician, healthy behaviors and improvement of information on healthy habits and 
behaviors that could derive in chronical illnesses), Participated in the health intervention is the variable of interest: a dummy variable that takes the value of one if student $i$ takes the health intervention, $X_{i}$ is a matrix of student pre-treatment characteristics and $e_{i}$ is the error term.

Two students who were assigned to the control group managed to receive treatment. As a result, the group who finally received treatment differs slightly from the group initially selected to be treated (the intention to treat group, ITT). An OLS regression may result in biased estimates if selection into the treatment group is not random. Therefore, we use the ITT variable -the initial status that resulted from the randomization - as an instrument for effective participation and estimate the effects using instrumental variables. By doing this, we use the random assignment to predict the actual participation in the intervention. Our assumption is that the outcome is affected by the random assignment only through changes in the intervention take-up. We describe the first stage regression of the 2SLS model in equation (2):

Participated in health intervention $_{i}=d+$ fRandomly assigned to health intervention ${ }_{i}+X_{i}^{\prime} g+h_{i}$

Where the variable Participated in health intervention ${ }_{i}$ is a dummy variable that documents the take-up of the program, Randomly assigned to health intervention $i$ is a dummy variable with the results from randomization into control and treatment group, $X_{i}$ is a matrix of student characteristics and $h_{i}$ is the error term. As a robustness check, we also use the initial assignment - Randomly assigned to health intervention ${ }^{-}$ as the explanatory variable in equation (1) -results from these regressions are available upon request.

In Table 3, we investigate the effects of the health intervention on the acquisition of information related to healthy habits. Students took a test of 18 questions and received a grade of 10 if all the questions were answered correctly. We present the results of the regression on the number of correct answers, the test grade and the adjusted grade considering the difficulty of the questions ${ }^{5}$. Results indicate that the health intervention improved the test score in 1.27 points and in 1.31 points when controlling for difficulty - this represents approximately a $23 \%$ increase in the score compared to the control group. Being randomly assigned to the control group derives in answering $52 \%$ of the questions correctly when not considering difficulty and $37 \%$ when considering difficulty. Those assigned to the health intervention had a better performance in both cases. Figure 1 shows the difference in the cumulative distribution function of the test scores with and without adjustment for difficulty. Those randomly assigned to the health intervention outperform those assigned to the control group.

[Insert Table 3]

\footnotetext{
${ }^{5}$ We constructed a special index that takes into account the relative difficulty of the questions in the test. The formula assigned greater weight to those questions that were answered correctly less frequently by students. For each question i (of 18), we constructed a dummy variable $d_{i}$ that takes the value of one if the student answered correctly and zero otherwise. The index is defined as follows: $\sum_{i}\left[1-\operatorname{mean}\left(d_{i}\right)\right] d_{i} /$ $\sum_{i}\left[1-\right.$ mean $\left.\left(d_{i}\right)\right]$. We obtain a number between zero and one and multiply by 10 . As a result, we obtain the test grade adjusting for difficulty of the questions.
} 
We also report the effect of participating in the health intervention on health behaviors and health objective indicators. Though the coefficients on smoking and SPB (Systolic Blood Pressure) are statistically significant when differences are taken at the ten and five percent level respectively, overall we are not able to affirm that there is an effect of the treatment on outcomes (there are no significant differences between the two groups on 14 of the 16 outcome variables).

\section{[Insert Table 4]}

We explore the different effects of the intervention on participants that prior to the health seminar exercised less than 150 minutes ( 2.5 hours) a week and on those who exercised more than 150 minutes per week. We consider this threshold because it represents the minimum amount of time devoted to exercise advisable to prevent chronical diseases (Physical Activity Guidelines Advisory Committee, 2008). About $50 \%$ of the population of students exercises less than the minimum at the baseline survey. The distribution of students is presented in Figure 2.

\section{[Figure 2]}

In Table 5, we present the results considering the interaction effects with the amount of exercise practiced prior to the Health Intervention. For this purpose, we consider the threshold of 2.5 hours per week. We would like to estimate the following equation:

$$
\begin{aligned}
& Y_{i}=a+b \text { Participated in health intervention }{ }_{i}+c \text { Participated in health intervention }{ }_{i} \text { * } \\
& \text { Less than } 2.5 \text { hours }_{i}+\mathrm{d} \text { Less than } 2.5 \text { hours }_{i}+X_{i}^{\prime} e+f_{i}
\end{aligned}
$$

Where $Y_{i}$ is the outcome of interest for student $\mathrm{i}$ (health indicators measured by physician, healthy behaviors and behaviors that could derive in chronical illnesses), Participated in health intervention ${ }_{i}$ is a dummy variable that takes the value of one if student $i$ takes the health intervention, Less than 2.5 hours $_{i}$ is a dummy variable that takes the value of one if the student $\mathrm{i}$ exercises less than 2.5 hours a week,

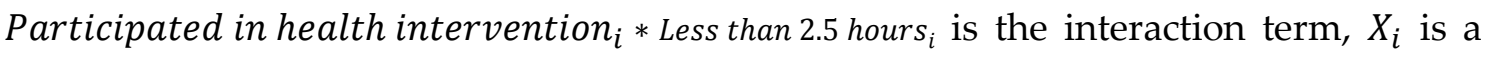
matrix of student pre-treatment characteristics and $f_{i}$ is the error term.

We instrument Participated in the health intervention and Participated in the health intervention *Less than 2.5 hours using the exogenous variables Randomly assigned to participate in the health intervention and Randomly assigned to participate in the health intervention* Less than 2.5 hours.

We find that being randomly assigned to the intervention does not modify habits for those who exercised less than 2.5 hours per week. This result differs from the findings of Calzolari and Nardotto (2015) who find that reminders increase the amount of exercise of low-attendance students to the gym.

[Insert Table 5] 


\section{Discussion}

The results of this health intervention show that students who were subject to the treatment improved the information but were not able to translate knowledge into a healthier behavior, neither reported nor objectively measured by a physician. From the competing hypothesis regarding the effects of our intervention, we are not able to reject the null hypothesis, which stated that participants would not change behavior. Fryer (2013) in his model explains that activities, which require effort such as studying or exercising, may be difficult to achieve. It could happen that providing information regularly is not enough to modify behavior. If future rewards are perceived as very distant in the future, participants could consider the benefits not worth their effort.

Moreover, improvement in health might depend on factors not included in the intervention. Investment in programs that provide information and remind individuals on the importance of exercise might be effective when bolstered with financial incentives to exercise. Once the students engage in healthier activities and increment their attendance to gym or practice more sports, the acquisition of information could help to achieve a balanced diet and to avoid risky behaviors. Another factor to consider is the complementarity between health investments in time. Cunha and Heckman (2007) develop a model of skill formation that explains facts and observations on human development and diversity. The formation of physical health capital is modelled (Heckman, 2007) taking into account the pivotal importance of early child investments in this area and the dynamic complementarity of investments - skills acquired at one stage raise the productivity of investment at later stages. If there were no previous health interventions or no remedial interventions in adolescence, the present health intervention should be reinforced by future health programs.

In future interventions, we will incorporate environmental factors in the analysis such as family support and peer effects. Physical activities are affected by personal, social and environmental factors (Heath et al., 2012). Interventions that include those various levels are the most successful way to increase physical activity (Bauman et al., 2012). Testing whether more tailored messages could change behaviors and improve healthy habits is one complementarity worth exploring. Lavecchia, Liu and Oreopoulos (2014) suggest that personal assistance -one-to-one coaching - is more intense than textmessages reminders, which could be easily ignored. For example, providing communication with role models such as TV stars, athletes or hiring a doctor who could advice frequently might be stimulating for college students. They recommend this approach because it could help to "get things done", to reduce anxiety about making mistakes, to receive detailed information and review and to increase empowerment. It would be extremely important to show the effectiveness of guidance in order to have high take-up of participants and to detail a structured program to avoid procrastination and to engage students in a continuous process.

Another possible explanation for our results is that students in the intervention were overconfident, they acquired the information on the average risks of unhealthy behaviors but they thought these were not relevant or applied to them. 
We do not rule out the possibility that the lack of significance could be due to the small sample size. Future research should attempt to increase the sample size, for instance pooling cohorts. Other explanation for the absence of effects is that students were already in good or very good health before the intervention, and, on average, they practice the recommended amount of sports. There was little room to improve health outcomes in this setting. This observation also points to the external validity of our results. They are limited to undergraduate students who are similar to those who signed up to participate in the health intervention (students who attend a private university, have similar socio-demographic characteristics and are interested in the relationship between health and academic achievement). So, there can be room for a positive impact of an intervention of these characteristics (intensive health seminar and weekly reminders using ICTs) in other sub-populations (i.e.: students with poorer healthy habits).

\section{Conclusion}

Our findings suggest that a combined intervention -health seminar and following messages through SMS, Facebook Group and through the student's intranet webpage does not derive in better behaviors, though students acquire more information on healthy habits. Knowledge was measured with a test where those assigned to the treatment group answered $64 \%$ of the questions correctly (vs $52 \%$ in the control group). Adjusting for difficulty, on a grading scale from 1 to 10 , those randomly assigned to the health intervention received, on average, a grade of 5, whereas those randomly assigned to the control group received a grade of 3.7. These two differences are statistically significant.

There were no improvements in healthy behaviors or health indicators (measured by self-reports and by a physician). Results do not change when we consider the interaction effects with the amount of exercise practiced prior to the Health Intervention. We considered the threshold of 2.5 hours a week because it represents the minimum amount of time devoted to exercise advisable to prevent chronical diseases (Physical Activity Guidelines Advisory Committee, 2008).

Overall, we cannot reject the null standard hypothesis, which stated that participants would not change behavior. One explanation is that benefits of exercising are perceived as very distant and therefore students may prefer not to invest in costly activities. Also, improvement in health might depend on other elements. The intervention could be bolstered with financial incentives or with tailored assistance in order to engage students in exercising more frequently. Another explanation could be that students are overconfident and presume that the information acquired on average risks does not apply to them. However, we are aware that the lack of significance could be due to the small sample size. 


\section{References}

Balsa, A., Gandelman, N., \& Porzecanski, R. (2010). The impact of ICT on adolescent's perceptions and consumption of substances. IDB Working Paper Series, № IDB-WP219.

Bauman, A. E., Reis, R. S., Sallis, J. F., Wells, J., Loos, R. J. F., \& Martin, B. W. (2012). Correlates of physical activity: why are some people physically active and others not? The Lancet, 380 (9838), 21-27.

Blanchflower, D. G., Oswald, A. J., \& Stewart-Brown, S. (2013). Is psychological wellbeing linked to the consumption of fruit and vegetables? Social Indicators Research, 114(3), 785-801.

Calfas, K. J., Sallis, J. F., Nichols, J. F., Sarkin, J. A., Johnson, M. F., Caparosa, S., Thompson, S., Gehrman, C. A., \& Alcaraz, J. E. (2000). Project GRAD: Two-year outcomes of a randomized controlled physical activity intervention among young adults. American journal of preventive medicine, 18(1), 28-37.

Calzolari, G., \& Nardotto, M. (2015). Nudging with information: a field experiment. Available at: http://www2.dse.unibo.it/calzolari/web/papers/CalzolariNardottoNudge.pdf

Charness, G., \& Gneezy, U. (2009). Incentives to exercise. Econometrica, 77(3), 909-931.

Cunha, F. and Heckman, J. J. (2007). The technology of skill formation. American Economic Review, 97(2):31-47.

Deslandes, A., Moraes, H., Ferreira, C., Veiga, H., Silveira, H., Mouta, R., \& Laks, J. (2009). Exercise and mental health: many reasons to move. Neuropsychobiology, 59(4), 191.

Djuric, Z., Ellsworth, J. S., Ren, J., Sen, A., \& Ruffin, M. T. (2010). A randomized feasibility trial of brief telephone counseling to increase fruit and vegetable intakes. Preventive medicine, 50(5), 265-271.

Dietary guidelines for Americans. (2010). 7th Edition, Washington, DC: U.S. Government Printing Office. U.S. Department of Agriculture and U.S. Department of Health and Human Services.

Fjeldsoe, B. S., Marshall, A. L., \& Miller, Y. D. (2009). Behavior change interventions delivered by mobile telephone short-message service. American Journal of Preventive Medicine, 36(2), 165-173.

Fryer Jr, R. G. (2013). Information and student achievement: evidence from a cellular phone experiment (No. w19113). National Bureau of Economic Research. 
Heath, G. W., Parra, D. C., Sarmiento, O. L., Andersen, L. B., Owen, N., Goenka, S., Montes, F., \& Brownson, R. C. (2012). Evidence-based intervention in physical activity: lessons from around the world. The Lancet, 380(9838), 272-281.

Heckman, J. J. (2007). The economics, technology, and neuroscience of human capability formation. Proceedings of the National Academy of Sciences, 104(33), 1325013255.

Hivert, M. F., Langlois, M. F., Berard, P., Cuerrier, J. P., \& Carpentier, A. C. (2007). Prevention of weight gain in young adults through a seminar-based intervention program. International journal of obesity, 31(8), 1262-1269.

Lavecchia, A. M., Liu, H., \& Oreopoulos, P. (2014). Behavioral economics of education: progress and possibilities (No. w20609). National Bureau of Economic Research.

Lee, I. M., Shiroma, E. J., Lobelo, F., Puska, P., Blair, S. N., \& Katzmarzyk, P. T. (2012). Effect of physical inactivity on major non-communicable diseases worldwide: an analysis of burden of disease and life expectancy. The Lancet, 380(9838), 219-229.

Levitsky, D. A., Garay, J., Nausbaum, M., Neighbors, L., \& DellaValle, D. M. (2006). Monitoring weight daily blocks the freshman weight gain: a model for combating the epidemic of obesity. International journal of obesity, 30(6), 1003-1010.

McEachan, R. R., Lawton, R. J., Jackson, C., Conner, M., Meads, D. M., \& West, R. M. (2011). Testing a workplace physical activity intervention: a cluster randomized controlled trial. Int J Behav Nutr Phys Act, 8(29), 1-12.

Physical activity guidelines advisory committee report. (2008). Washington, DC: US. Department of Health and Human Services.

Reimers, C. D., Knapp, G., \& Reimers, A. K. (2012). Does physical activity increase life expectancy? A review of the literature. Journal of Aging Research, 2012.

Warburton, D. E., Nicol, C. W., \& Bredin, S. S. (2006). Health benefits of physical activity: the evidence. Canadian Medical Association Journal, 174(6), 801-809.

Woolford, S. J., Clark, S. J., Strecher, V. J., \& Resnicow, K. (2010). Tailored mobile phone text messages as an adjunct to obesity treatment for adolescents. Journal of Telemedicine and Telecare, 16(8), 458-461. 


\section{Table 1 - Description of Baseline Characteristics}

\begin{tabular}{|c|c|c|c|c|c|}
\hline & $\begin{array}{c}(1) \\
\text { Mean }\end{array}$ & $\begin{array}{c}(2) \\
\text { S.D. }\end{array}$ & $\begin{array}{c}(3) \\
\text { Min } \\
\end{array}$ & $\begin{array}{c}(4) \\
\text { Max } \\
\end{array}$ & $\begin{array}{c}(5) \\
\text { \# Obs. }\end{array}$ \\
\hline Age & 21.908 & 2.902 & 18 & 31 & 67 \\
\hline Capital of Uruguay & 0.662 & 0.477 & 0 & 1 & 68 \\
\hline Good or very good economic well-being & 0.721 & 0.452 & 0 & 1 & 68 \\
\hline
\end{tabular}

\begin{tabular}{|c|c|c|c|c|c|}
\hline \multicolumn{6}{|l|}{ Academic \& Labor Environment } \\
\hline Average Grade & 6.800 & 2.685 & 0 & 10 & 68 \\
\hline Credits earned & 148.059 & 99.605 & 0 & 339 & 68 \\
\hline Scholarship at Universidad de Montevideo (UM) & 0.323 & 0.471 & 0 & 1 & 68 \\
\hline Majoring in Management & 0.221 & 0.418 & 0 & 1 & 68 \\
\hline Majoring in Accountancy & 0.397 & 0.493 & 0 & 1 & 68 \\
\hline Majoring in Economics & 0.147 & 0.357 & 0 & 1 & 68 \\
\hline High School 1 & 0.074 & 0.263 & 0 & 1 & 68 \\
\hline High School 2 & 0.074 & 0.263 & 0 & 1 & 68 \\
\hline High School 3 & 0.074 & 0.263 & 0 & 1 & 68 \\
\hline Started college in 2009 & 0.147 & 0.357 & 0 & 1 & 68 \\
\hline Started college in 2010 & 0.088 & 0.286 & 0 & 1 & 68 \\
\hline Started college in 2011 & 0.265 & 0.444 & 0 & 1 & 68 \\
\hline Started college in 2012 & 0.250 & 0.436 & 0 & 1 & 68 \\
\hline Started college in 2013 & 0.103 & 0.306 & 0 & 1 & 68 \\
\hline Not working & 0.612 & 0.491 & 0 & 1 & 67 \\
\hline \multicolumn{6}{|l|}{ Health Behavior \& Household Environment } \\
\hline \multicolumn{6}{|l|}{ Smoking } \\
\hline Has smoke at least once in his/her life & 0.478 & 0.503 & 0 & 1 & 67 \\
\hline Currently Smoking & 0.438 & 0.504 & 0 & 1 & 32 \\
\hline Nobody smoke at home in the last 7 days & 0.567 & 0.499 & 0 & 1 & 67 \\
\hline \multicolumn{6}{|l|}{ Alcohol } \\
\hline Consumed alcohol in the last 12 months & 0.940 & 0.239 & 0 & 1 & 67 \\
\hline $\begin{array}{l}\text { In the last } 12 \text { months consumes alcohol from } 1 \text { to } 3 \text { times a } \\
\text { month }\end{array}$ & 0.508 & 0.504 & 0 & 1 & 63 \\
\hline $\begin{array}{l}\text { In the last } 12 \text { months consumes alcohol from } 1 \text { to } 4 \text { times a } \\
\text { week }\end{array}$ & 0.270 & 0.477 & 0 & 1 & 63 \\
\hline Consumed alcohol in the last 30 days & 0.761 & 0.430 & 0 & 1 & 67 \\
\hline \multicolumn{6}{|l|}{ Healthy Habits \& Perceptions } \\
\hline Days a week that eats vegetables & 4.328 & 2.245 & 0 & 7 & 67 \\
\hline Days a week that eats fruits & 3.672 & 2.128 & 0 & 7 & 67 \\
\hline Hours devoted to walk or ride a bike per day & 0.876 & 0.837 & 0 & 5 & 67 \\
\hline Hours devoted to play sports per week & 2.567 & 2.090 & 0 & 6 & 67 \\
\hline Hours staying in a sitting or lying position per day & 6.570 & 3.422 & 1 & 13 & 67 \\
\hline Perceived fair health condition & 0.075 & 0.265 & 0 & 1 & 67 \\
\hline Perceived good health condition & 0.343 & 0.478 & 0 & 1 & 67 \\
\hline Perceived very good health condition & 0.522 & 0.503 & 0 & 1 & 67 \\
\hline Perceived excellent health condition & 0.060 & 0.239 & 0 & 1 & 67 \\
\hline \multicolumn{6}{|l|}{ Physician \& Treatment } \\
\hline Has controlled blood pressure at least once in his/her life & 0.940 & 0.239 & 0 & 1 & 67 \\
\hline Ever being told to have high blood pressure & 0.015 & 0.122 & 0 & 1 & 67 \\
\hline $\begin{array}{l}\text { Has been measured the level of blood cholesterol at least } \\
\text { once in his/her life }\end{array}$ & 0.597 & 0.494 & 0 & 1 & 67 \\
\hline Weight (self-reported) & 65.552 & 12.111 & 44 & 95 & 67 \\
\hline Has consulted a physician in the last 12 months & 0.881 & 0.327 & 0 & 1 & 67 \\
\hline Has consulted a dentist in the last 12 months & 0.761 & 0.430 & 0 & 1 & 67 \\
\hline
\end{tabular}


Table 2 - Mean Comparison of Baseline Characteristics. Group Subject to Randomization

\begin{tabular}{|c|c|c|c|c|c|c|}
\hline & $\begin{array}{c}(1) \\
\text { Treatment }\end{array}$ & $\begin{array}{c}(2) \\
\text { Control }\end{array}$ & $\begin{array}{c}(3) \\
\text { Difference }\end{array}$ & $\begin{array}{c}(4) \\
\text { Std.Error }\end{array}$ & $\begin{array}{c}(5) \\
\text { p-value }\end{array}$ & $\begin{array}{c}\text { (6) } \\
\text { \# Obs. }\end{array}$ \\
\hline \multicolumn{7}{|l|}{ Socio-Demographic Characteristics } \\
\hline Age & 22.094 & 21.727 & -0.367 & 0.713 & 0.609 & 67 \\
\hline Female & 0.576 & 0.600 & 0.024 & 0.121 & 0.842 & 68 \\
\hline Capital of Uruguay & 0.697 & 0.629 & -0.068 & 0.116 & 0.558 & 68 \\
\hline Good or very good economic well-being & 0.727 & 0.714 & -0.013 & 0.111 & 0.907 & 68 \\
\hline
\end{tabular}

\begin{tabular}{|c|c|c|c|c|c|c|}
\hline \multicolumn{7}{|l|}{ Academic and Labor Environment } \\
\hline Average Grade & 6.961 & 6.649 & -0.312 & 0.655 & 0.635 & 68 \\
\hline Credits earned & 167.758 & 129.486 & -38.272 & 23.891 & 0.114 & 68 \\
\hline $\begin{array}{l}\text { Scholarship at Universidad de Montevideo } \\
\text { (UM) }\end{array}$ & 0.303 & 0.343 & 0.040 & 0.115 & 0.730 & 68 \\
\hline Majoring in Economics & 0.182 & 0.114 & -0.068 & 0.087 & 0.439 & 68 \\
\hline Majoring in Accountancy & 0.333 & 0.457 & 0.124 & 0.120 & 0.304 & 68 \\
\hline Majoring in Management & 0.273 & 0.171 & -0.101 & 0.101 & 0.321 & 68 \\
\hline High-School 1 & 0.061 & 0.086 & 0.025 & 0.064 & 0.697 & 68 \\
\hline High-School 2 & 0.121 & 0.029 & -0.093 & 0.063 & 0.148 & 68 \\
\hline High-School 3 & 0.091 & 0.057 & -0.034 & 0.064 & 0.600 & 68 \\
\hline Started college in 2009 & 0.182 & 0.114 & -0.068 & 0.087 & 0.439 & 68 \\
\hline Started college in 2010 & 0.121 & 0.057 & -0.064 & 0.069 & 0.359 & 68 \\
\hline Started college in 2011 & 0.242 & 0.286 & 0.043 & 0.109 & 0.691 & 68 \\
\hline Started college in 2012 & 0.182 & 0.314 & 0.132 & 0.105 & 0.213 & 68 \\
\hline Started college in 2013 & 0.091 & 0.114 & 0.023 & 0.075 & 0.756 & 68 \\
\hline Not Working & 0.667 & 0.559 & -0.108 & 0.120 & 0.373 & 67 \\
\hline
\end{tabular}

\begin{tabular}{|c|c|c|c|c|c|c|}
\hline Health Behavior E Environment & & & & & & \\
\hline \multicolumn{7}{|l|}{ Smoking } \\
\hline Has smoked at least once in his/her life & 0.576 & 0.382 & -0.193 & 0.122 & 0.117 & 67 \\
\hline Currently Smoking & 0.474 & 0.385 & -0.089 & 0.184 & 0.631 & 32 \\
\hline Nobody smoke at home in the last 7 days & 0.455 & 0.676 & 0.222 & 0.120 & 0.069 & 67 \\
\hline \multicolumn{7}{|l|}{ Alcohol } \\
\hline Drank alcohol in the last 12 months & 0.970 & 0.912 & -0.058 & 0.058 & 0.324 & 67 \\
\hline $\begin{array}{l}\text { In the last } 12 \text { months consumes alcohol from } 1 \\
\text { to } 3 \text { times a month }\end{array}$ & 0.406 & 0.613 & 0.207 & 0.125 & 0.104 & 63 \\
\hline $\begin{array}{l}\text { In the last } 12 \text { months consumes alcohol from } 1 \\
\text { to } 4 \text { times a week }\end{array}$ & 0.313 & 0.226 & -0.087 & 0.113 & 0.446 & 63 \\
\hline Consumed alcohol in the last 30 days & 0.727 & 0.794 & 0.067 & 0.105 & 0.528 & 67 \\
\hline \multicolumn{7}{|l|}{ Healthy Habits \& Perceptions } \\
\hline Days a week that eats vegetables & 4.121 & 4.529 & 0.408 & 0.551 & 0.461 & 67 \\
\hline Days a week that eats fruits & 3.606 & 3.735 & 0.129 & 0.524 & 0.806 & 67 \\
\hline Hours devoted to walk or ride a bike per day & 0.944 & 0.809 & -0.136 & 0.205 & 0.511 & 67 \\
\hline Hours devoted to play sports per week & 2.131 & 2.990 & 0.859 & 0.504 & 0.093 & 67 \\
\hline $\begin{array}{l}\text { Hours staying in a sitting or lying position per } \\
\text { day }\end{array}$ & 6.929 & 6.221 & -0.709 & 0.838 & 0.401 & 67 \\
\hline Perceived excellent health condition & 0.091 & 0.029 & -0.061 & 0.058 & 0.295 & 67 \\
\hline Perceived very good health condition & 0.394 & 0.647 & 0.253 & 0.120 & 0.039 & 67 \\
\hline Perceived good health condition & 0.424 & 0.265 & -0.160 & 0.116 & 0.174 & 67 \\
\hline
\end{tabular}


Physician E Treatment

\begin{tabular}{|c|c|c|c|c|c|c|}
\hline $\begin{array}{l}\text { Has controlled blood pressure at least once in } \\
\text { his/her life }\end{array}$ & 0.970 & 0.912 & -0.058 & 0.058 & 0.324 & 67 \\
\hline $\begin{array}{l}\text { Has been measured the level of blood } \\
\text { cholesterol at least once in his/her life }\end{array}$ & 0.636 & 0.559 & -0.078 & 0.121 & 0.525 & 67 \\
\hline Ever being told to have high blood pressure & 0.000 & 0.029 & 0.029 & 0.030 & 0.328 & 67 \\
\hline Weight (self-reported) & 65.818 & 65.294 & -0.524 & 2.981 & 0.861 & 67 \\
\hline Has consulted a physician in the last 12 months & 0.818 & 0.941 & 0.123 & 0.079 & 0.124 & 67 \\
\hline Has consulted a dentist in the last 12 months & 0.788 & 0.735 & -0.053 & 0.106 & 0.620 & 67 \\
\hline $\begin{array}{l}\text { Has been admitted to hospital in the last } 12 \\
\text { months }\end{array}$ & 0.061 & 0.088 & 0.028 & 0.065 & 0.673 & 67 \\
\hline
\end{tabular}


Table 3 - Effects of the health program on acquisition of health information

(1)

Number of correct answers
(2)

Test Grades
(3)

Test Grade (considering difficulty)

First Stage

$0.925^{* * *}$

$(0.000)$

[18.053]

\begin{tabular}{lccc}
\hline Participated in Health & $2.293^{* * *}$ & $1.274^{* * *}$ & $1.310^{* * *}$ \\
Intervention & $(0.002)$ & $(0.002)$ & $(0.002)$ \\
& & & -0.073 \\
Age & -0.123 & -0.069 & $(0.293)$ \\
& $(0.311)$ & $(0.311)$ & 0.204 \\
Female & 0.384 & & $(0.620)$ \\
& $(0.588)$ & 0.213 & \\
Capital of Uruguay & & $(0.588)$ & 0.243 \\
& 0.853 & & $(0.606)$ \\
Good or very good economic & $(0.312)$ & 0.474 & -0.071 \\
well-being & 0.286 & $(0.312)$ & $(0.882)$ \\
\hline r2 & $(0.732)$ & 0.159 & 0.150 \\
$\mathrm{~N}$ & 0.180 & $(0.732)$ & 63 \\
\hline
\end{tabular}

Summary Statistics on Acquisition of Health Knowledge

\begin{tabular}{|c|c|c|c|c|}
\hline & \multicolumn{2}{|c|}{ Treatment } & \multicolumn{2}{|c|}{ Control } \\
\hline & $\begin{array}{c}\text { Mean } \\
(4)\end{array}$ & $\begin{array}{l}\text { S.D. } \\
(5)\end{array}$ & $\begin{array}{l}\text { Mean } \\
(6)\end{array}$ & $\begin{array}{l}\text { S.D. } \\
(7)\end{array}$ \\
\hline Number of correct questions & 11.549 & 2.589 & 9.387 & 2.929 \\
\hline Test Grade & 6.441 & 1.438 & 5.215 & 1.627 \\
\hline $\begin{array}{l}\text { Test Grade (considering } \\
\text { difficulty) }\end{array}$ & 4.980 & 1.549 & 3.748 & 1.639 \\
\hline $\mathrm{N}$ & 32 & 32 & 31 & 31 \\
\hline \multicolumn{5}{|c|}{$\begin{array}{l}\text { Notes: } 2 \text { SLS regression controlling for heteroscedasticity where variable 'Participated in Health Intervention' is } \\
\text { instrumented by 'Randomly assigned to Health Intervention'. } p \text {-values in parentheses; }{ }^{*} p<0.1,{ }^{* *} p<0.05,{ }^{* * *} p<0.01 \text {. } \\
\text { Coefficient from variable 'Randomly assigned to Health Intervention' in the First Stage -regression }(2) \text {-is displayed: } \\
p \text {-values in parentheses and t-statistics in brackets. Similar results were obtained with OLS and ITT and } 2 S L S \\
\text { estimations, with and without controls and are available upon request. Controlling for baseline covariates } \\
\text { unbalanced due to attrition provides similar results. The test had } 18 \text { questions related to healthy habits and risky } \\
\text { behaviors. The test grade was calculated by dividing the number of correct answers by the total number of questions } \\
\text { and multiplying by } 10 \text {. We constructed a special index that takes into account the relative difficulty of the questions } \\
\text { in the test. The formula assigned greater weight to those questions that were answered correctly less frequently by } \\
\text { students. For each question i (of } 18) \text {, we constructed a dummy variable } d_{i} \text { that takes the value of one if the student } \\
\text { answered correctly and zero otherwise. The index is defined as follows: } \sum_{i}\left[1-\text { mean }\left(d_{i}\right)\right] d_{i} / \sum_{i}\left[1-\text { mean }\left(d_{i}\right)\right] \text {. We } \\
\text { obtain a number between zero and one and multiply by } 10 \text {. As a result, we obtain the test grade adjusting for } \\
\text { difficulty of the questions. We also provide summary statistics by intention to treat variable of outcomes on } \\
\text { acquisition of information. }\end{array}$} \\
\hline
\end{tabular}




\section{Figure 1}
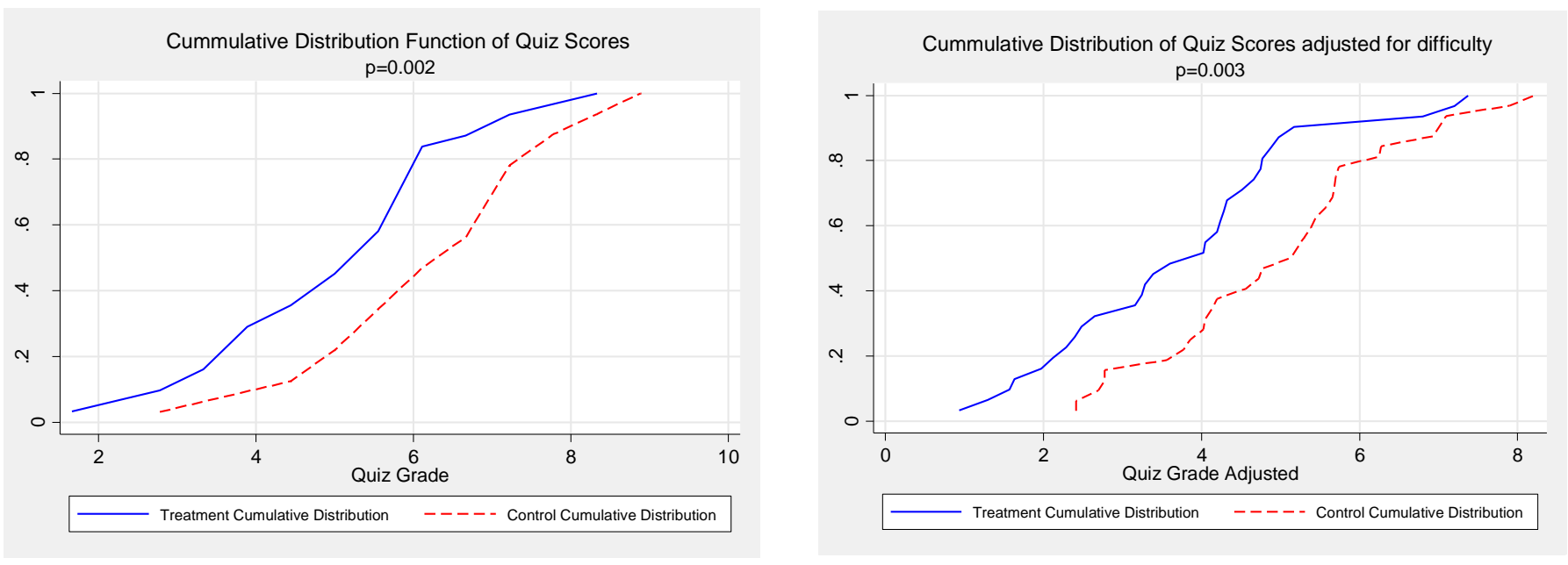

Figure 1. The test had 18 questions related to healthy habits and risky behaviors. The test grade was calculated by dividing the number of correct answers by the total number of questions and multiplying by 10. We constructed a special index that takes into account the relative difficulty of the questions in the test. The formula assigned greater weight to those questions that were answered correctly less frequently by students. For each question i (of 18), we constructed a dummy variable $d_{i}$ that takes the value of one if the student answered correctly and zero otherwise. The index is defined as follows: $\sum_{i}\left[1-\operatorname{mean}\left(d_{i}\right)\right] d_{i} /$ $\sum_{i}\left[1-\right.$ mean $\left.\left(d_{i}\right)\right]$. We obtain a number between zero and one and multiply by 10 . As a result, we obtain the test grade adjusting for difficulty of the questions. Numbers above the charts are p-values testing the equality of means of the test scores for the treatment and control groups. 
Table 4 - Effect of the Health Intervention on outcome variables

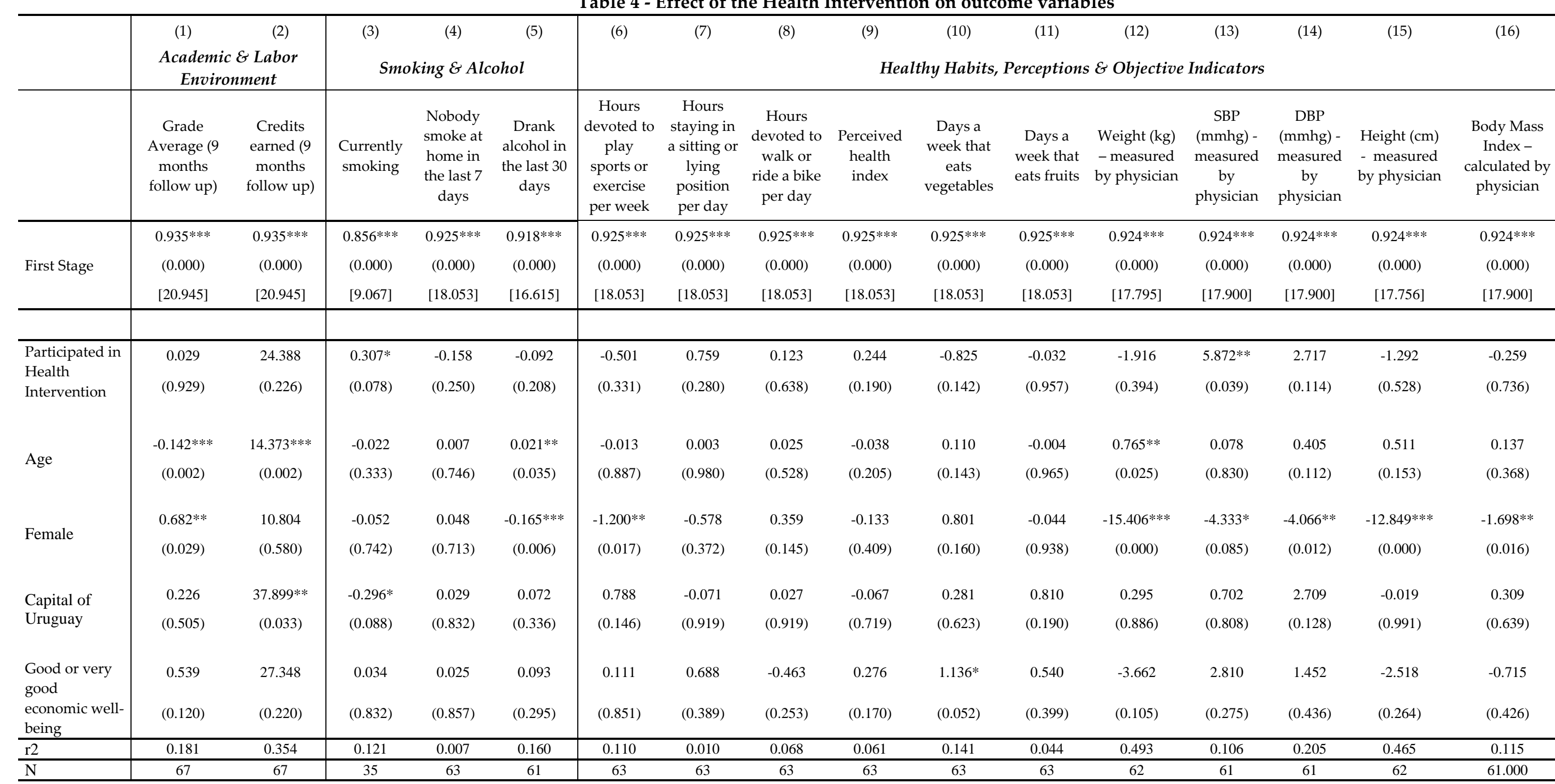

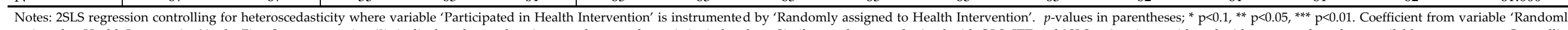

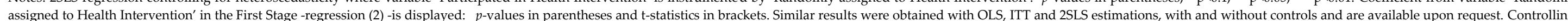
for baseline covariates unbalanced due to attrition and for baseline outcome in each regression provides similar results. SBP acronym for Systolic Blood Pressure and DBP acronym for Diastolic Blood Pressure. 
Figure 2

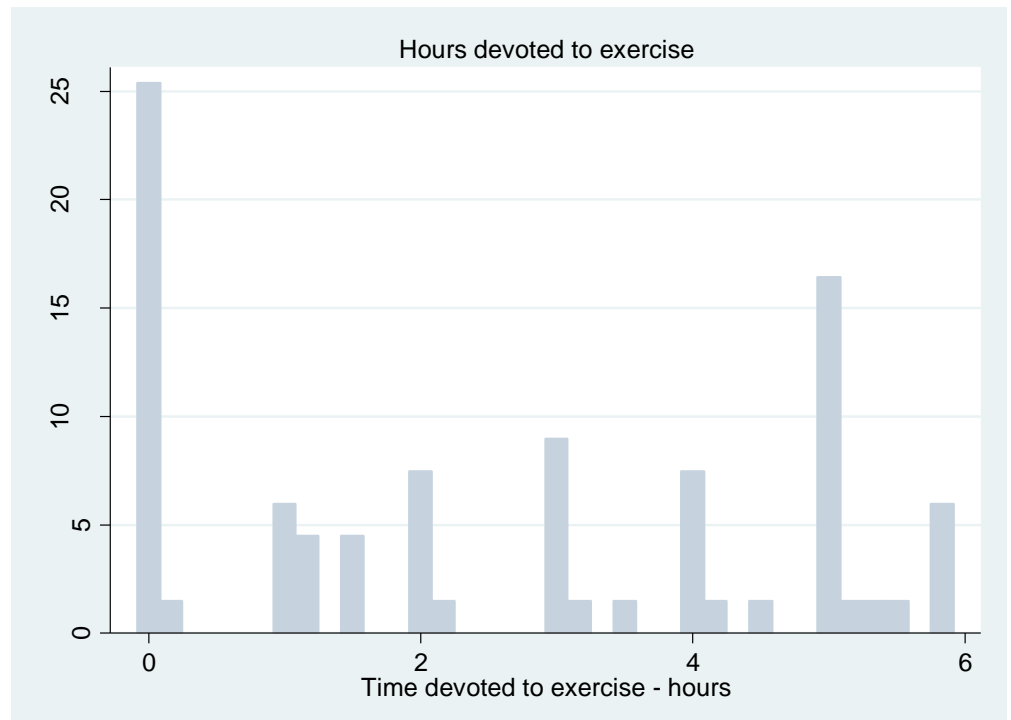

Figure 2. The figure shows the percentage of students according to time devoted to exercise (hours a week). 
Table 5 - Effect of the Health Intervention on outcome variables considering interaction effects

$\begin{array}{llllllllll}(1) & (2) & (3) & (4) & (5) & (6) & (7) & \text { (8) } & \text { (9) } & \text { (10) }\end{array}$

Healthy Habits, Perceptions \& Objective Indicators Environment

Smoking \& Alcohol

(14)

(15)

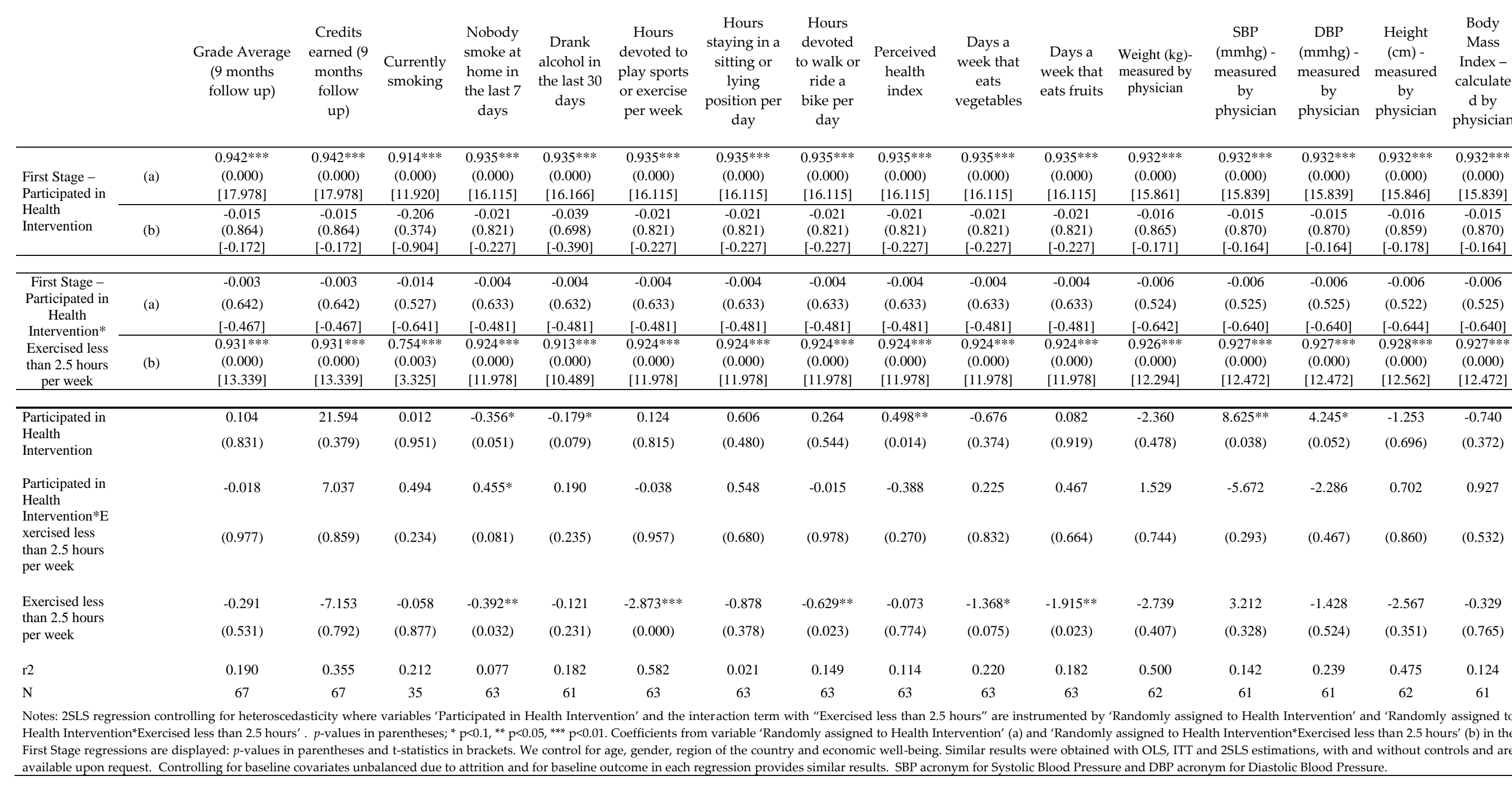

